\title{
No-tillage Planter's Stubble Breaking Device Modeling and Finite Element Analysis of the Disc
}

\author{
Wang Hongli \\ College of Engineering \\ Heilongjiang Bayi Agricultural University \\ DaQing, China \\ e-mail:wh108172003@yahoo.com.cn
}

\begin{abstract}
The Stubble breaking device is one of the most important components of the no-tillage planter. It directly influences the stubble breading effect, and even the performance of the complete machine. By the 3D parametric modeling software Pro/Engineer, 3D solid modeling of the stubble breaking device's parts was carried out. And the parts were assembled into the assembly with $\mathbf{p r o} / \mathrm{E}$. Then finite element analysis of the strain and stress on the key part (the ripple disc sickle) has been carried out. The result expresses that the intensity and stiffness of the ripple disc can satisfy the design specification, which provides a theory basis for the design and optimization of the stubble breaking device.
\end{abstract}

Keywords-No-tillage planter, Stubble breaking device, Ripple disc, Finite Element Method

\section{INTRODUCTION}

The no-tillage planter is the essential implement in the mechanization work of the no-till planting. As the operating performance of the stubble breaking is the key influencing factor of the no-till planter work, it is requested to have the good performance of anti-blocking[1-3]. The stubble breaking device with the ripple disc has been designed in this article. It is by the ripple disk that it cuts off straw covering in the ground, which will avoid the jam which is caused by straw entangling the furrow opener or clamping between two furrow openers. The ripple disk first shuts off the straw and then buried, and cuts open the surface. As the straw distribution, the straw moisture content, the soil texture are varied, in addition the soil has been influenced by the perturbation factor such as the stone, it is very difficult that the stress and deflection of the ripple disk are accurately calculated during operation, and that the strength and the rigidity are checked. Therefore, this article makes use of the parametric design software Pro/Engineer to model the stubble breaking device. And the stress and the deflection of the key part - ripple disk has been analyzed with FEA. The stress distribution map and the deflection chart were obtained, which provided the theory basis for the design and the optimization of the stubble breaking device.

\section{THE 3-D MODEL ESTABLISHMENT OF THE STUBBLE BREAKING DEVICE}

The stubble breaking device is mainly composed of the ripple disk, the eccentric shaft, the support, the rack of the ripple disc and so on. The preliminary design about the various parts of the breaking stubble device is completed by the empirical data. Then its characteristic parameters such as geometry size, tolerance precision, materials behavior, structure principle, assembly relations are determined.

According to the Pro/E Parameterized modeling technology, the parts database what we needed has been made on the basis of analyzing various parts size parameter and the restrain. Three-dimensional model of the needed main parts of the stubble breaking device is established by Pro/E[2]. As shown in Figure.1. Then according to the parts' size restraint characteristic, the various needed components are assembled to a whole with the virtual assembled technology[3]. Subsequently, the interference inspection and the whole inspection were made. If the question had been discovered in the inspection, the parametric redesign would be made, and the structure or the size would be changed. After all of the components are assembled, assembly model is shown in Figure.2.

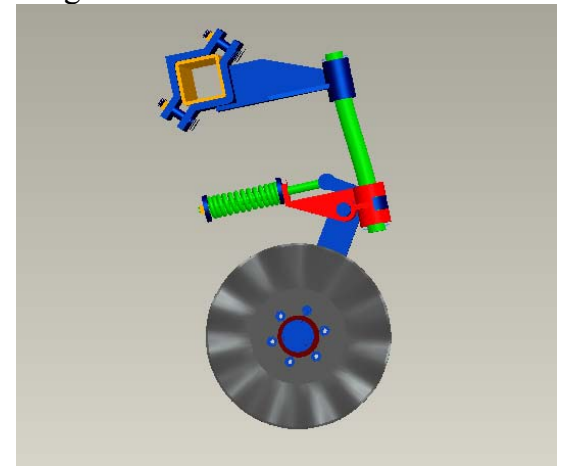

Figure 2. The virtual assembly system model of the Stubble breaking device 


\section{THE FINITE ELEMENT MODEL ESTABLISHMENT OF THE RIPPLE DISC}

As it is the seamless integration between Mechanica and Pro/Engineer, solid model of the ripple disc can be imported into Mechanica.

A. Setting the material properties

Material properties are set, and then material is distributed. The ripple disc is made of $65 \mathrm{Mn}$, its main performance parameter is shown in Table.1.

\section{B. Defining Constraint}

Because the disc shaft and the ripple disc are connected by the bolts which are uniformly distributed around the center hole of the ripple disc, constraint is exerted on the end of the center hole to analyze the stress and deformation state of the blade at the limit. On the nodal point where the displacement is constrained, a constraint condition is established according to the actual conditions. There are 6 constraints around the center hole, so the total freedoms of all nodal points are constrained around the center hole of the ripple disc. Thus it can make loading simple while solving.

\section{Applying load}

The ripple disc is mainly subjected to the cutting resistance (cutting force) and the cutting soil resistance[6]. The former is used to cut off the straw of the earth's surface, and the latter is used to cut to break an earth's surface and to crowd out the soil. So the load analysis is divided into the force cutting computation and the soil cutting force computation. The cutting resistance is related not only with the straw's mechanical physical property, cutter's material, geometric parameter, but also with the straw's support pattern and the ripple disk's cutting speed. The test indicate: the ripple disc cuts the straw of the earth's surface with the support, that is, the cutting edge will press the straw of earth's surface toward the ground firstly, and then it proceeds to cut with the support of the earth surface. This kind of cutting with the support requests the lower velocity, and cuts off very well[7-8]. After the ripple disc cuts off straw, it will continue turning and cut open an earth surface. At this time, the disc blade orifice is subjected to a holdup action. The soil produces resistance to the disc blade orifice. At the same time, the ripple disc is subjected to the extrusion of the both soil sides, and the soil has the resistance to the side edge of the knife tooth.

In the process of working, cutting force and cutting soil force change with variation of the disc angular at every point of the ripple disc. But what the finite element analysis mainly considers is stiffness check and strength check, so calculation can be made only at the maximum load, and maximum cutting resistance doesn't vary with the variation of the disc location, as shown in Figure.3. The maximum cutting soil resistance will be generated when disc cutting depth is up to the maximum. No-tillage sowing requests that cutting soil depth of the stubble breaking knife should be more than $80 \mathrm{~mm}$. According to the test, resistance of cutting the soil is $1946 \mathrm{~N}$ at this depth, resistance of cutting the straw is $265 \mathrm{~N}$. Figure. 3 is the ripple disc model plot of applying constraints and loading.

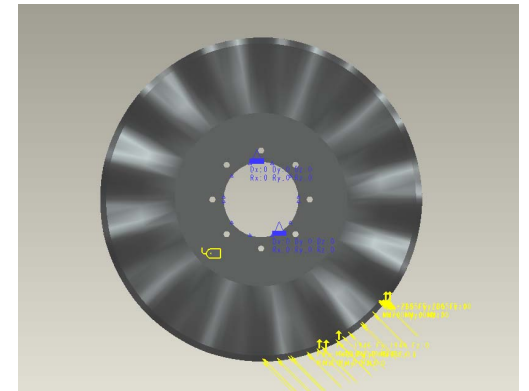

Figure 3. The model plot of applying constraints and loading

\section{Meshing}

Mechanica can complete meshing automatically. Meshing can be also completed by using the meshing tool AutoGEM. It is very necessary that it makes use of AutoGEM to separate the model for avoiding a automatically meshing making mistake during the analysis. Use AutoGEM setup to control the meshing parameter, so unit shape is the tetrahedron, the biggest ratio of width to height is 30 , number of nodes at the pattern edge is 3 , first/last nodal interval ratio is 1.0. After the unit mesh is established by using AutoGEM, the ripple disc is totally divided into 2846 tetras, 5237 edges and 68 faces are received. Because force analysis of the ripple disc is mainly in the cutting edge, mesh is much denser at the mesh of cutting edge, and the mesh is sparser on the other places than at the cutting edge. Figure. 4 is the meshing result of the ripple disc.

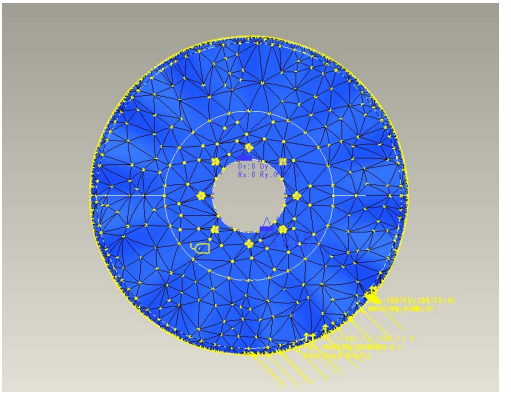

Figure 4. The FEA model of the ripple disc after meshing

\section{FINITE ELEMENT ANALYSIS OF THE RIPPLE DISC}

A. Defining static analysis

Select order "Analysis" $\rightarrow$ "Mechanica Analyses/Studies", build"New Static", determine convergence Method is Single-Pass Adaptive, which can decrease the time of calculation.

If the result of error checking were without mistake, structure static analysis could be carried out. After the system operates for two minutes, calculation result will be solved.

\section{B. Calculation result analysis}

By the static finite method analysis of the ripple disc, stress distribution condition and displacement contour of the ripple disc are shown as Figure.5, maximum/minimum mises stress and displacement is shown as Table.2. 
From Figure.5, on the whole, the stress is bigger at the lower-right edge(the region cutting soil and straw) of the ripple disc, and the lower rim of the center hole exists stress concentration, and the stress concentration gradually decreases outward. The maximum mises stress appears at the end of the cutting straw edge, for $35.97 \mathrm{Mpa}$. The minimum stress value appears at the top of the ripple disc, for $0.0034 \mathrm{Mpa}$. From Figure.6, the displacement is bigger at the lower-right edge (the region cutting soil and straw) of the ripple disc, and the maximum displacement appears at the end of the cutting straw edge, about $0.08 \mathrm{~mm}$. Displacement is much smaller. The biggest stress and strain of the ripple disc are all within the allowable range, namely the structural strength and stiffness meet design request. There is stress concentration around the center hole of the disc, so a clamping flange plate must be designed. As diameter and thickness of the flange plate is the primary factors assuring disc rigidity, according to the stress contour plot and the displacement contour plot of the disc, the diameter of the flange plate cloud takes for the $150 \mathrm{~mm}$, the thickness is a 18 $\mathrm{mm}$, and material is gray cast iron.

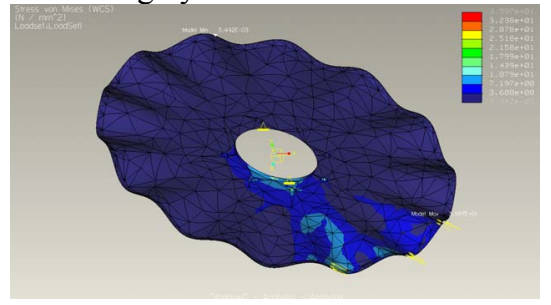

Figure 5. Mises stress contour plot of the ripple disc

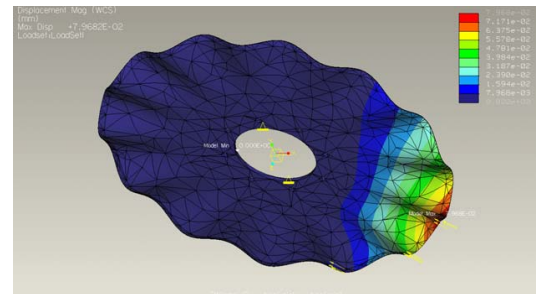

Figure 6. Displacement contour plot of the ripple disc

\section{CONCLUSION}

From the finite element analysis to the ripple disc, stress is comparatively centralized at the lower-right edge (the region cutting soil and straw) and the lower rim of the center hole, and maximum stress is $35.97 \mathrm{Mpa}$. As material of the disc is $65 \mathrm{Mn}$, its yield limit intensity is $430 \mathrm{Mpa}$. This value is bigger than the maximum stress of the disc, so the intensity of the disc is enough. The lower-right edge (the region cutting soil and straw) of the disc has bigger displacement, and maximum displacement value is $0.08 \mathrm{~mm}$. As this displacement value is smaller, rigidity of the disc is enough.

As the disc is mostly placed in the stress transition region, and the stress is smaller, work is safe and reliable.

By Pro/E, 3D parametric solid modeling about the stubble breaking device was made, meshing was carried out, the finite element model was created, displacement and stress was analyzed, and the probable failure location was pointed out. This will provide a reliable basis for further improving design and optimization. This method may speed up the speed of modeling, increases the design precision, and provide the efficient path to the stress analysis and the strength calculation of the components.

\section{ACKNOWLEDGMENT}

This thesis is supported by Heilongjiang Province Land Reclamation Bureau Projects(HNK10A-09-02-04), Heilongjiang Province Education Department Projects (12511359) , Heilongjiang Bayi Agricultural University Postdoctoral project.

\section{REFERENCES}

[1] MA Hong-liang; GAO Huan-wen; LI Hong-wen. Experimental Study on Corn Stalk and Rootstalk Cutting by Driven Disc. Transactions of the Chinese Society for Agricultural Machinery[J], 2007.38,PP 47-50.

[2] WANG Qing-jie; HE Jin; YAO Zong-lu. Design and Experiment on Powered Disc No-tillage Planter for Ridge-tillage. Transactions of the Chinese Society for Agricultural Machinery[J], 2008.39,PP 68-72.

[3] LI Hong-wen; CHEN Jun-da; DENG Jian. Study on Technology and Machines of Mechanized Conservation Tillage for Dryland Maize. Journal of China Agricultural University[J], 2000.5, PP68-72.

[4] HUANG Wei-dong; REN Guo-dong. Pro/ENGINEER Wildfire 2.0 Practical Guide[M],Bejing: China Forestry Publishing House.2007.

[5] LI Ya-jun; HUANG Hao. Virtual Prototype Technology \& its Application. Aeronautical Manufacturing Technology[J], 2002.2, PP36-38.

[6] LI Bao-fa. Agricultural Machinery[M],Beijing:China Agriculture Publishing House.2003.

[7] LUO Hong-qi; GAO Huan-wen; LIU An-dong. Study on Ridge-till and No-till Corn Planter. Transactions of the Chinese Society for Agricultural Machinery[J], 2006.37, PP 45- 47, 63.

[8] LI Wei; LI Wen-ying; MA Hong-liang. Study on the Driven Disc Cutting Mechanism of the No-tillage Planter in the Soil Bin. Journal of Agricultural Mechanization Research[J], 2006.28, PP 139- 141. 


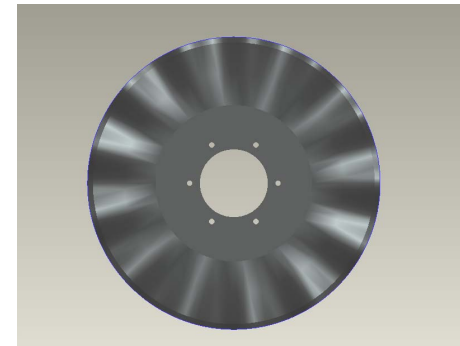

(a) Ripple disc

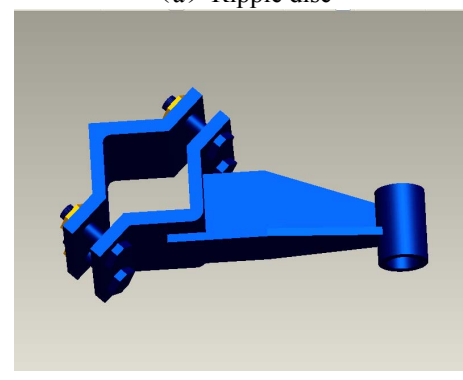

(c) Support

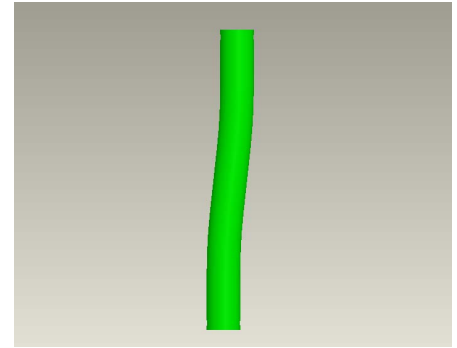

(b) Eccentric shaft

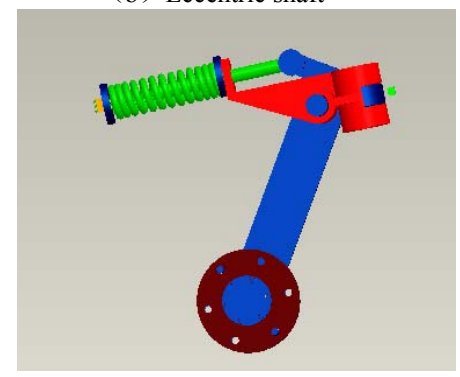

(d) Rack of the ripple disc

Figure 1. The main parts modeling of the Stubble breaking device

TABLE I. MATERIAL PERFORMANCE PARAMETER OF THE RIPPLE DISC

\begin{tabular}{|c|c|c|c|c|}
\hline $\begin{array}{c}\text { Material } \\
\text { trademark }\end{array}$ & $\begin{array}{c}\text { Young modulus } \\
(\mathbf{G P a})\end{array}$ & Poisson's ratio & $\begin{array}{c}\text { Mass density } \\
\left(\mathbf{k g} / \mathbf{m}^{\mathbf{3}}\right)\end{array}$ & $\begin{array}{c}\text { Tensile strength } \\
\mathbf{( M P a})\end{array}$ \\
\hline $65 \mathrm{Mn}$ & 226 & 0.300 & 7810 & 735 \\
\hline \multicolumn{5}{|c|}{ TABLE II. FINITE ELEMENT ANALYSIS RESULT DATA } \\
\hline Part & $\begin{array}{c}\text { Maximum } \\
\text { mises stress } \\
(\mathbf{M P a})\end{array}$ & $\begin{array}{c}\text { Minimum } \\
\text { stress (MPa) }\end{array}$ & $\begin{array}{c}\text { Maximum } \\
\text { displacement } \\
(\mathbf{m m})\end{array}$ & $\begin{array}{c}\text { Allowable } \\
\text { stress (MPa) }\end{array}$ \\
\hline Ripple disc & $3.597 \mathrm{e}+01$ & $3.442 \mathrm{e}-03$ & $7.968 \mathrm{e}-02$ & $1.410 \mathrm{e}+02$ \\
\hline
\end{tabular}

